\section{Soil Pasteurization and Mycorrhizal Inoculation Alter Flower Production and Corm Composition of Brodiaea laxa 'Queen Fabiola'}

\author{
C.F. Scagel ${ }^{1}$ \\ U.S. Department of Agriculture, Agricultural Research Service, Horticultural \\ Crops Research Unit, 3420 NW Orchard Avenue, Corvallis, OR 97330
}

Additional index words. Glomus intraradices, arbuscular mycorrhizae, wild hyacinth

\begin{abstract}
The ornamental flowering bulb Brodiaea laxa Benth. 'Queen Fabiola' was grown with or without arbuscular mycorrhizal fungal (AMF) inoculum in pasteurized or nonpasteurized soil to determine if inoculation altered flower and corm production. The first growing cycle after planting, mycorrhizal inoculation decreased the days to anthesis and increased the number of flowers produced per inflorescence and flower longevity. It also affected the quality of the daughter corm, which influenced flowering the following year. Inoculated plants produced larger daughter corms and more cormels than uninoculated plants, and allocated more biomass to the corms than the cormels, which lowered the average weight of the cormels. Corms produced by inoculated plants also had higher concentration of nitrogen, potassium, zinc, and nonreducing sugars than those produced by uninoculated plants. The beneficial effects of AMF inoculation on flowering and corm/cormel production were generally increased by soil pasteurization. The results indicate that mycorrhizal inoculation may enhance commercial cut flower and corm production of this crop.
\end{abstract}

Arbuscular mycorrhizal fungi (AMF) are known to enhance nutrient uptake and increase growth and production in many plant species (Smith and Read 1997). Field-grown Easter lily form mycorrhizae with species of arbuscular mycorrhizal fungi (AMF) that are also capable of forming associations with onion (Ames and Linderman, 1977) and soil fertility level influences colonization by AMF (Ames et al., 1976). Inoculation of Easter lily with AMF increases root and stem weight (Ames and Linderman, 1978) and plant response to inoculation can vary with soil fertility (Ames and Linderman, 1978) and growing season (Mora, 1990). Except for onion (Giovannetti and Riess, 1980; Tawaraya, et al., 1999) and Easter lily (Lilium longiflorum Thunb.) (Ames and Linderman, 1977; Ames et al., 1976; Linderman et al., 1975; Mora, 1990), however, little is known about the benefits of AMF on lilaceous bulb crops (Scagel, 2002).

Furthermore, few reports detail how different carbon and nutrient allocation patterns between mycorrhizal plants and nonmycorrhizal plants can influence flowering (Bryla and Koide, 1998; Johnson et al., 1982) and bulb production (Charron et al., 2001). Carbon and nutrient allocation patterns can influence

Received for publication 2 Oct. 2002. Accepted for publication 6 June 2003. The author wishes to thank Kathy Eggemeyer, Ben Jackson, Lisa Tribbet, and Jesse Mitchell for technical assistance. Mention of trademark, proprietary product, or vendor does not constitute a guarantee or warranty of the product by the U.S. Dept. of Agriculture and does not imply its approval to the exclusion of other products or vendors that also may be suitable.

${ }^{1}$ Research plant physiologist; e-mail scagelc@onid. orst.edu. bulb quality of liliaceous ornamentals. Bulb quality can, in turn, effect new bulb formation and flower production and is influenced by several factors during storage (temperature, moisture) and during the growing season (light, nutrients, temperature) (Han, 1993; Han and Halvey, 1993; Han et al., 1990; Marinangeli and Curvetto, 1997; Miller and Langhans, 1989; Suh, 1997).

The objective of this study was to determine whether addition of AMF inoculum into the growing medium of $B$. laxa 'Queen Fabiola' alters aspects of flower production, corm production, and corm quality. Brodiaea laxa is a late-spring flowering corm (bulb) in the Themidaceae family that grows from summer dormant corms (De Hertogh and Le Nard, 1993). Brodiaea produces an umbellate inflorescence with many flowers on one scape that is used for cut flower production. Flower initiation in this genus occurs after planting. The size of the apical meristem in the corm rather than the amount of reserves in the corm is thought to determine the corm's ability to form flowers (Halvey, 1990).

\section{Materials and Methods}

Mycorrhizal inoculum. Glomus intraradices Schenck \& Smith was originally obtained from Native Plants Inc., (Salt Lake City, Utah) and maintained in pot cultures at the USDA-ARS, Horticultural Crops Research Laboratory, in Corvallis, Ore. The fungus was propagated in pot cultures on roots of bunching onion (Allium cepa L. 'White Lisbon') grown in 1 loam : 1 sand for 5 months. Inoculum consisted of a mixture of the soil medium, extraradical hyphae and spores, and colonized root segments ( $<2 \mathrm{~mm}$ in length). Population estimates of the inoculum used in this study by the MPN method (Woomer, 1994) were on average 10 propagules/g of soil medium.

Plant material and treatments. Corms of wild hyacinth (B. laxa 'Queen Fabiola') were planted into cylindrical 3.78 -L pots (Lerio $19.4 \times 18.1 \mathrm{~cm}$ ) filled with a steam pasteurized $\left(60^{\circ} \mathrm{C}\right.$ for $\left.30 \mathrm{~min}\right)$ or nonpasteurized $1: 1$ mixtures of Willamette Valley alluvial silt loam and river sand. The mixture had $11 \mathrm{mg} \cdot \mathrm{kg}^{-1}$ available phosphorus and a $\mathrm{pH}$ of 6.3. AMF inoculum ( $G$. intraradices), which contained spores, colonized root fragments, and other propagules in a sand-based carrier at a rate of $1: 166(\mathrm{v} / \mathrm{v})$, was placed beneath the base of each corm at planting. For controls, sterilized inoculum was added at the base of each corm at the same rate.

Cultural conditions. During the first growing cycle, plants were maintained in a glasshouse with supplemental light (16 h light/8 $\mathrm{h}$ dark) provided by high-pressure multi-vapor lamps with an average of 700 $\mu \mathrm{mol} \cdot \mathrm{m}^{-2} \cdot \mathrm{s}^{-1}$ at canopy level, and average day/night temperatures of $20 / 16{ }^{\circ} \mathrm{C}(75 / 65$ $\left.{ }^{\circ} \mathrm{F}\right)$. Plants were fertilized once a week with $50 \mathrm{~mL}$ of a liquid fertilizer (LF) $(10 \% \mathrm{~K}, 10 \%$ $\mathrm{P}, 40 \% \mathrm{~N}, 20 \% \mathrm{Ca}, 7 \% \mathrm{Mg}, 8 \% \mathrm{~S}, 4 \% \mathrm{Na}$, and $<0.05 \%$ of $\mathrm{Mn}, \mathrm{Cu}, \mathrm{Zn}, \mathrm{B}$, and $\mathrm{Mo}$ ) and watered as needed. Periodic pest and pathogen control measures were performed as needed and included Diflubenzuron for fungus gnats (Bradysia sp.), Neoseiulus fallacis Garman predators for spider mites (Tetranychus sp.), and Neoseiulus cucumeris predators for thrips (Frankiniella sp.). At the end of the first growing cycle, when shoots had died-back, corms were removed from the soil, dried at $20^{\circ} \mathrm{C}$ for 2 weeks, then stored at $5^{\circ} \mathrm{C}$ for 10 weeks. After 10 weeks of storage, corms were planted into cylindrical 3.78-L pots (Lerio $19.4 \mathrm{~cm} \times 18.1$ $\mathrm{cm})$ containing a 1:1 mixture of a Willamette Valley alluvial silt loam and river sand. Plants were grown under the same growing conditions for both the first and second growing cycles. To assess carryover effects from the first growing cycle, no AMF inoculation was included for the second growing cycle and soil was pasteurized as previously described.

First growing cycle measurements. For each corm, the number of days after planting until shoot emergence and flower emergence was recorded. The number of flowers per inflorescence and the length of flower survival on each plant was recorded. At the end of the growing cycle, when shoots had died-back, corms were removed from the soil, counted, air dried, and weighed. Colonization of fresh roots by AMF was assessed on 1-cm sections after clearing and staining by a modified procedure of Phillips and Hayman (1970), replacing lactophenol with lactoglycerin. Percentage of root length with colonization by AMF was estimated by the method of Biermann and Linderman (1980). Six daughter corms per treatment were dried and placed in storage. A subsample (six corms per treatment) was analyzed for $\mathrm{P}, \mathrm{K}, \mathrm{Ca}, \mathrm{Zn}$, $\mathrm{C}, \mathrm{N}$, and $\mathrm{S}$ concentrations using standard methods (Gaulak et al. 1997). Nitrogen and $\mathrm{S}$ were determined after automated combus- 


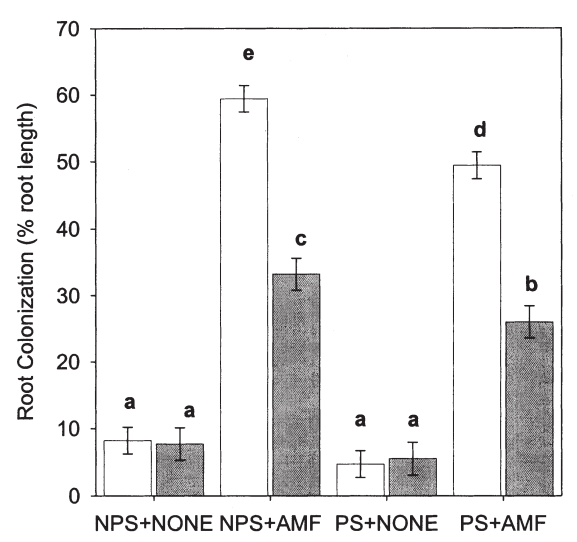

Soil Pasteurization and AMF Inoculation Treatments

Fig. 1. Influence of soil pasteurization and inoculation with the arbuscular mycorrhizal fungus (AMF) Glomus intraradices on root colonization of Brodiaea laxa 'Queen Fabiola' during the first (YR1) and second (YR2) growing cycle after inoculation. Error bars are standard error of the least squares means within each year (YR1, $\mathrm{n}=12),(\mathrm{YR} 2, \mathrm{n}=6) . \mathrm{NPS}+\mathrm{NONE}=$ no soil pasteurization and sterilized AMF inoculum, $\mathrm{NPS}+\mathrm{AMF}=$ no soil pasteurization and inoculated with AMF, PS+NONE = pasteurized soil, $\mathrm{PS}+\mathrm{AMF}=$ pasteurized soil and inoculated with AMF. Columns with the same letter above them are not significantly different from each other at $(P<0.05$, Bonferroni test $)$.

tion and concentrations of the remainder of the elements determined after dry ash oxidation by ICP-AES. Total soluble protein was determined colorimetrically using BIO-RAD (Coomassie Brilliant blue) (Bradford, 1976) after extraction of ground corm tissue $(<50$ mesh) in buffer (20 mm TRIS, $10 \mathrm{~mm} \mathrm{NaCl}$, $10 \mathrm{~mm} \mathrm{KCl}, 2 \mathrm{~mm} \mathrm{MgCl} \cdot 6 \mathrm{H}_{2} 0$ ) with Nonidet P-40. Total amino acid content of corms was determined colorimetrically with ninhydrin (Yemm and Cocking, 1955) after extraction with acetic acid before analysis. Total reducing and nonreducing sugar content of corms was determined colorimetrically using a modification of the Somolgyi-Nelson alkaline copper method (Dische, 1962; Nelson, 1944). Supernatant from ground corm tissue $(<50$ mesh) extracted with warm $80 \%$ ethanol was used to determine total reducing sugar content. The residual pellet from extraction was hydrolyzed in $0.2 \mathrm{~N} \mathrm{KOH}$ before analyses for nonreducing sugars.

Second growing cycle measurements. For each corm, the number of days after planting until shoot emergence and flower emergence was recorded. The total number of flowers per inflorescence on each plant was also recorded. At the end of the growing cycle, when shoots had died-back, corms were removed from the soil, counted, air dried, and weighed. Root colonization by mycorrhizal fungi was assessed as previously described.

Experimental design and statistical analyses. The experiment was set up in a completely randomized design with each treatment unit (pot) replicated 12 times during the first growing cycle and six times during the second growing cycle. Morphology and growth data were
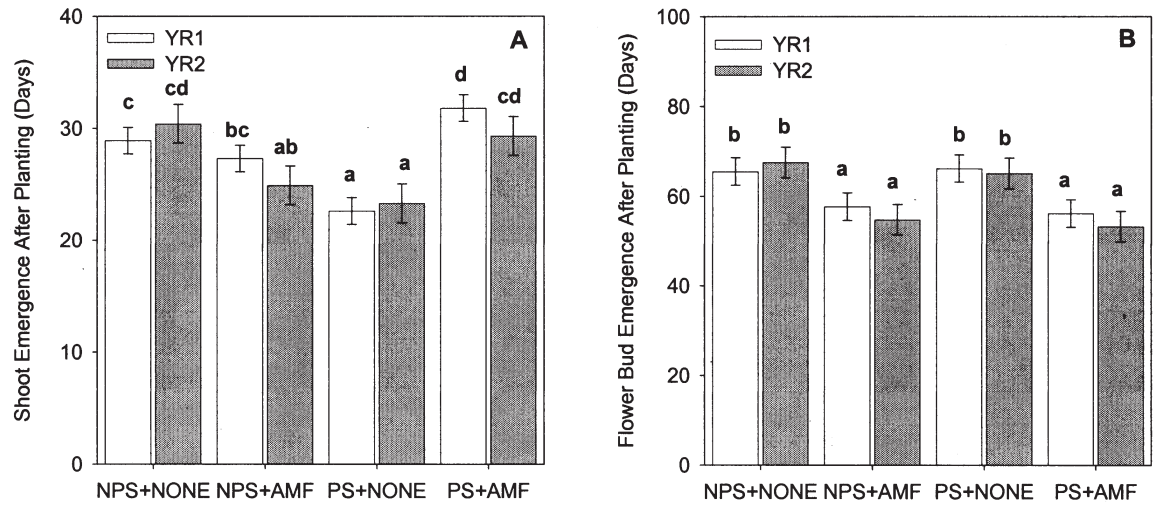

Soil Pasteurization and AMF Inoculation Treatments

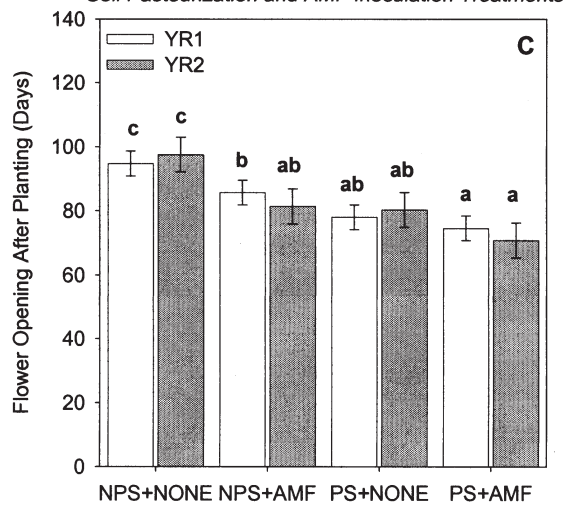

Soil Pasteurization and AMF Inoculation Treatments

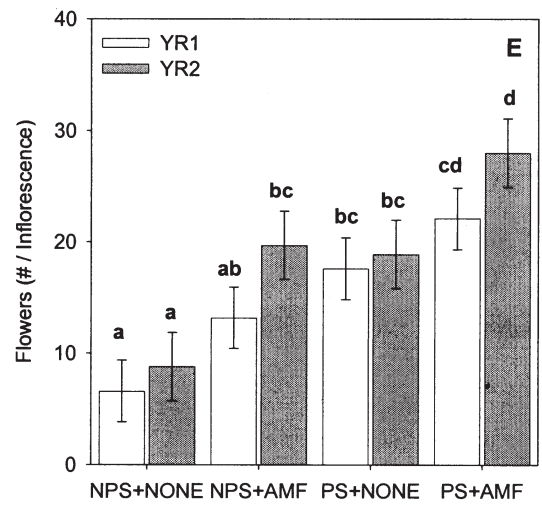

Soil Pasteurization and AMF Inoculation Treatments

subjected to analysis of variance (ANOVA) with soil pasteurization, AMF inoculation, and growing cycle from inoculation as main effects. Corm composition data were subjected to two-way ANOVA with soil pasteurization and AMF inoculation as main effects. Bonferroni test was used to separate treatment means $(P<0.05)$. All data analyses were performed using the Statistica statistical package (Statsoft, Tulsa, Okla., 1996).

\section{Results}

Root colonization by AMF. AMF inoculation significantly increased the proportion of root length colonized by fungi in both pasteurized and nonpasteurized soil, although pasteurization reduced colonization in inoculated plants by $17 \%$ in the first growing cycle after inoculation and by $22 \%$ in the second growing cycle (Fig. 1).

Shoot emergence. When plants were grown in pasteurized soil, AMF inoculation signifi-

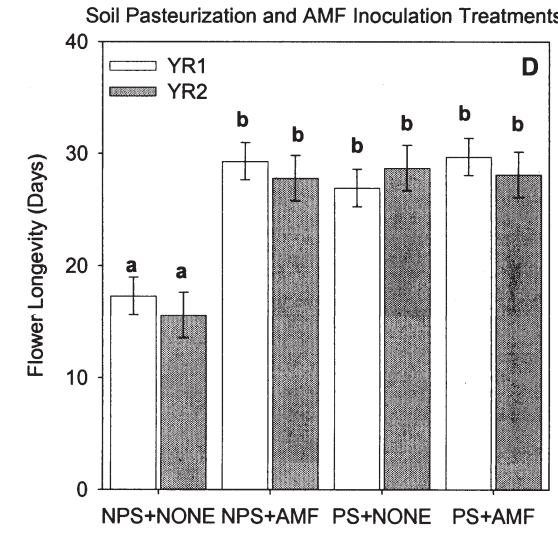

Soil Pasteurization and AMF Inoculation Treatments

Fig. 2. Influence of soil pasteurization and inoculation with the arbuscular mycorrhizal fungus (AMF) Glomus intraradices on stem emergence (A), flower bud emergence (B), flower opening (C), flower longevity (D), and flowers per inflorescence (E), and of Brodiaea laxa 'Queen Fabiola' during the first (YR1) and second (YR2) growing cycle after inoculation. Error bars are standard error of the least squares means within each year (YR1, $n=12),(Y R 2, n=6)$. NPS+NONE = no soil pasteurization and sterilized AMF inoculum, $\mathrm{NPS}+\mathrm{AMF}=$ no soil pasteurization and inoculated with AMF, PS+NONE = pasteurized soil, $\mathrm{PS}+\mathrm{AMF}=$ pasteurized soil and inoculated with AMF. Columns with the same letter above them are not significantly different from each other at $(P<0.05$, Bonferroni test $)$.

cantly increased the days to shoot emergence both the first and second growing cycle after planting (Fig. 2A). However, when they were grown in nonpasteurized soil, inoculation had no effect on shoot emergence the first growing cycle after planting and reduced days to shoot emergence the second growing cycle after planting (Fig. 2A).

Flower development. Inoculation significantly decreased the days to flower bud emergence (Fig. 2B) and flower opening (Fig. 2C) and increased the number of flowers produced per inflorescence in both growing cycles of the study whether soil was pasteurized or not (Fig. 2E). Inoculation also increased flower longevity in both growing cycles, but only when the soil was not pasteurized (Fig. 2D). Noninoculated plants stopped producing new flowers 4 to $8 \mathrm{~d}$ earlier than inoculated plants (data not shown). Pasteurization significantly increased the number of flowers per inflorescence in both inoculated and noninoculated treatments (Fig. 2E), and also increased flower 


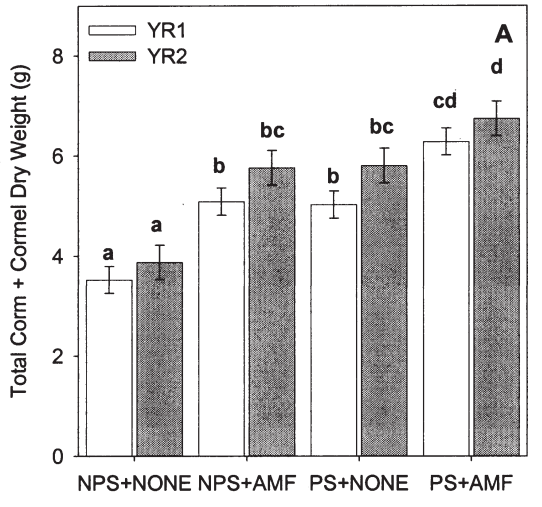

Soil Pasteurization and AMF Inoculation Treatments
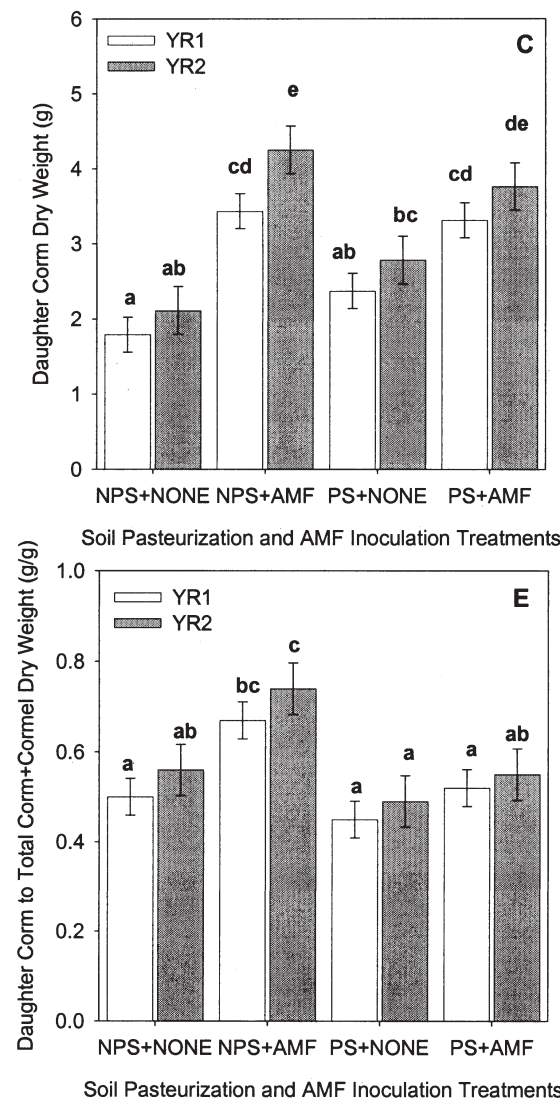

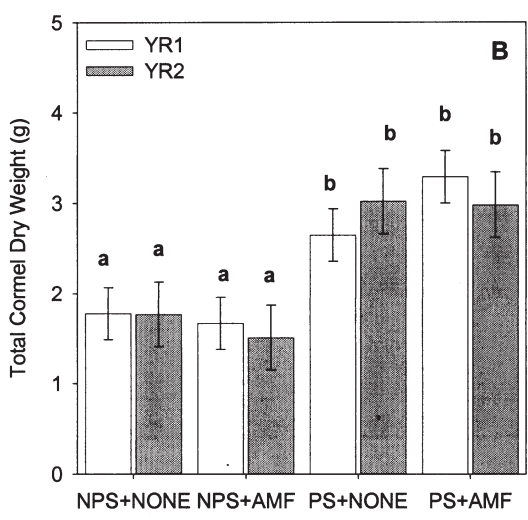

Soil Pasteurization and AMF Inoculation Treatments

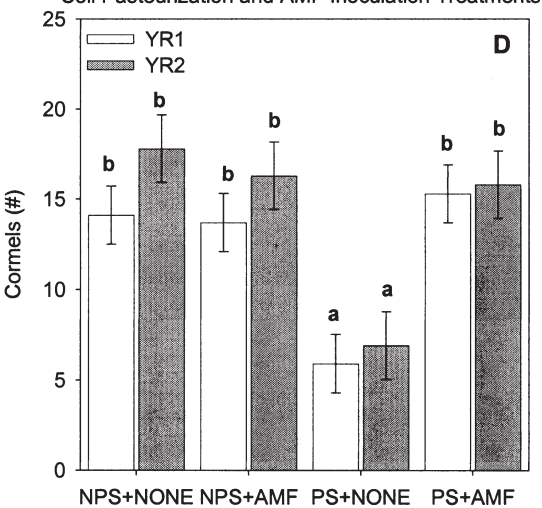

Soil Pasteurization and AMF Inoculation Treatments

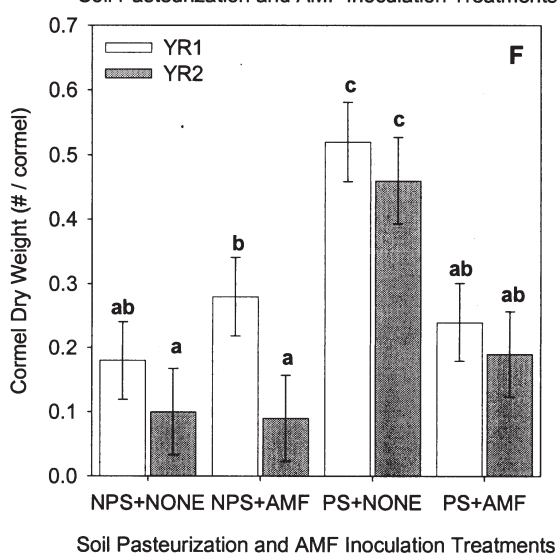

Fig. 3. Influence of soil pasteurization and inoculation with the arbuscular mycorrhizal fungus (AMF) Glomus intraradices on total weight of daughter corms and cormels (A), cormel weight (B), daughter corm weight $(\mathbf{C})$, number of cormels $(\mathbf{D})$, ratio of daughter corm weight to total weight (E), and average weight per cormel (F) of Brodiaea laxa 'Queen Fabiola' during the first (YR1) and second (YR2) growing cycle after inoculation. Error bars are standard error of the least squares means within each year (YR1, $n=12)$, (YR2, $n=6)$. NPS+NONE = no soil pasteurization and sterilized AMF inoculum, $\mathrm{NPS}+\mathrm{AMF}=$ no soil pasteurization and inoculated with AMF, PS+NONE = pasteurized soil, $\mathrm{PS}+\mathrm{AMF}$ = pasteurized soil and inoculated with AMF. Columns with the same letter above them are not significantly different from each other at $(P<0.05$, Bonferroni test).

longevity when plants were not inoculated (Fig. 2D). Plants growing in nonpasteurized soil stopped producing new flowers 8 to $12 \mathrm{~d}$ earlier than plants growing in pasteurized soil (data not shown).

Corm and cormel development and composition. Inoculation with AMF increased the total weight of daughter corms and cormels in both production cycles (Fig. 3A). Inoculation significantly increased the weight of daughter corms produced at the end of each growing cycle in both soils (Fig. 3C) and inoculated plants partitioned a higher proportion of bio- mass to daughter corms than cormels (Fig. 3E). Inoculation also increased the concentrations of nitrogen (Fig. 4C) and nonreducing sugars (Fig. 5D) in the corms produced in both soils, but lowered the concentrations of amino acids (Fig. 5B) and reducing sugars (Fig. 5C) at the end of the first growing cycle. Soil pasteurization increased the total weight of daughter corms and cormels (Fig. 3A); however, plants grown in pasteurized soil partitioned a proportion of biomass to cormels than to daughter corms (Fig. 3E). Pasteurization also increased the concentration of nitrogen in the corm at the end of the first growing cycle (Fig. 4C), but decreased the concentration of potassium (Fig. 4B) and reducing sugars (Fig. 5C). Pasteurization decreased the total number of cormels produced both growing cycles, but only when plants were not inoculated (Fig. 3D). The total weight of cormels produced, however, was increased by pasteurization whether plants were inoculated or not (Fig. 3B). Higher cormel production from inoculated plants growing in pasteurized soil resulted in a lower average weight per cormel than in noninoculated plants (Fig. 3F). Plants growing in nonpasteurized soil had the smallest cormels and plants growing in pasteurized soil without AMF inoculum had the largest cormels (Fig. 3F).

\section{Discussion}

Liliaceous plants are important in a wide variety of horticultural systems used for the production of food and ornamental crops. The beneficial effects of AMF on growth and nutrition of onion has been well documented in many experimental systems designed to look at the mechanisms involved in the interaction between the fungus and plant, however the influence of AMF on liliaceous plants that are used in the production of cut flowers and ornamental crops has not been investigated to a similar depth. We found that inoculation of $B$. laxa 'Queen Fabiola' bulbs with AMF can alter plant development and biomass partitioning which can, in turn influence crop productivity in terms of bulb and flower production and bulb composition.

In general, inoculation with AMF has been found to increase plant growth; however there are many reports which describe an initial lagphase after inoculation when noninoculated plants are larger than inoculated plants. Mora (1990) found that inoculation of L. longiflorum with the AMF $G$. intraradices significantly delayed shoot emergence of plants growing in pasteurized media in the growing cycle plants were inoculated. This delay in shoot emergence in pasteurized soil could be a result of an increase in carbohydrate demand during the early stages of root colonization and may potentially have a negative influence on the timing of production of $B$. laxa for cut flowers. In nonpasteurized soil inoculation with AMF had no effect on the time of shoot emergence during the first growing cycle, but reduced the number of days to emergence in the second growing cycle. This indicates when corms are grown in nonpasteurized soil, inoculation with AMF alter aspects of corm quality that influence the timing of shoot emergence in the growing cycle following inoculation.

In most geophytes, including $B$. laxa, the major factor controlling flowering is seasonal thermoperiodicity (Han et al., 1991; Rees, 1985). Although inoculation delayed shoot emergence of $B$. laxa, this delay did not cause a delay in the timing of flower emergence. Mora (1990) found that inoculation of $L$. longiflorum with $G$. intraradices did not significantly affect flower emergence or number of flowers produced although response varied with the type $\mathrm{N}$ fertilizer. Our results suggest that initial 

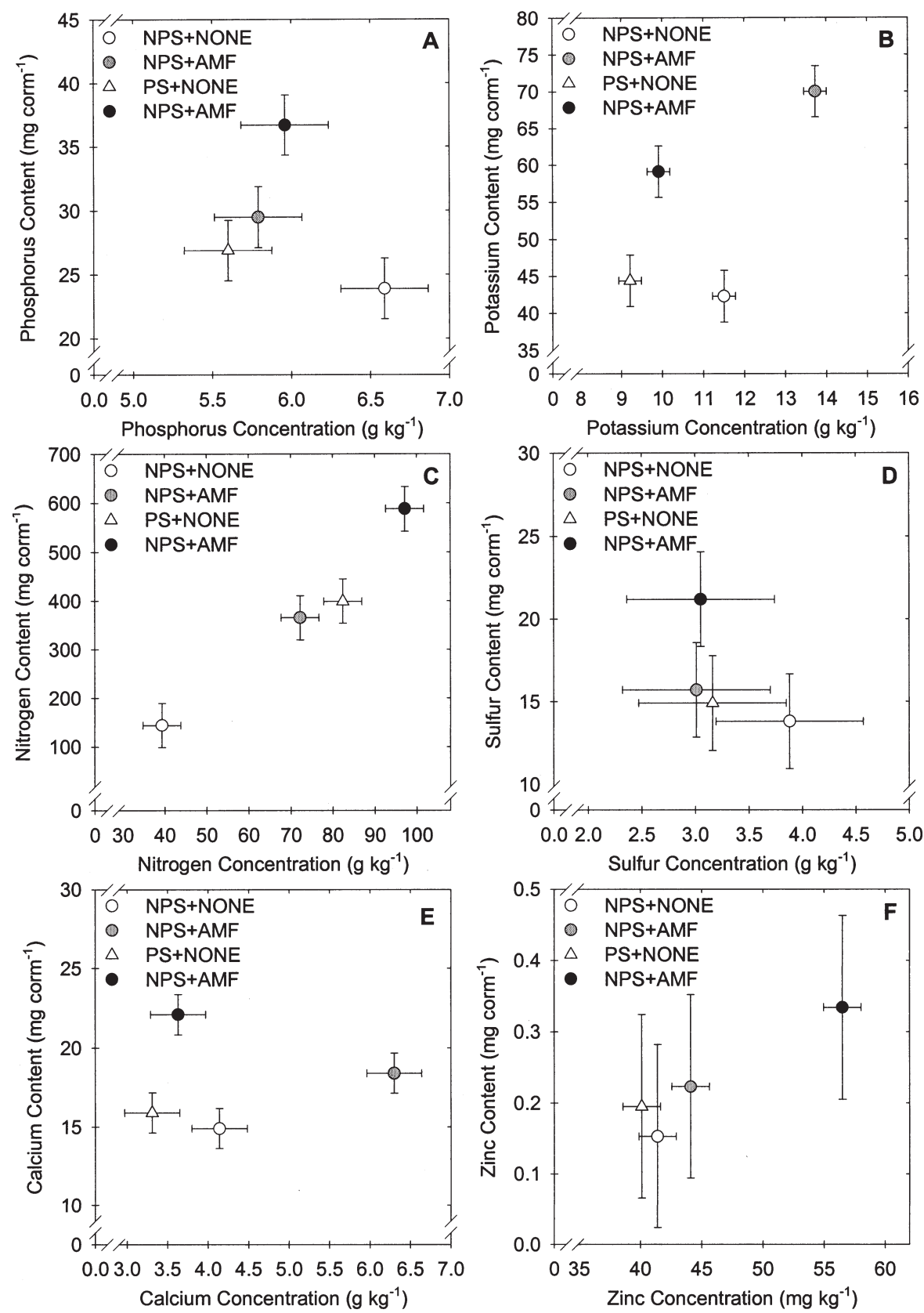

Fig. 4. Influence of soil pasteurization and inoculation with the arbuscular mycorrhizal fungus (AMF) Glomus intraradices on concentration and total content of phosphorus (A), potassium (B), nitrogen (C), sulfur (D), calcium (E), and zinc (F) in daughter corms of Brodiae a laxa 'Queen Fabiola' at the end of the first growing cycle after inoculation. Error bars are standard error of the least squares means $(n=12)$. NPS+NONE $=$ no soil pasteurization and sterilized AMF inoculum, $\mathrm{NPS}+\mathrm{AMF}=$ no soil pasteurization and inoculated with AMF, PS+NONE = pasteurized soil, PS+AMF = pasteurized soil and inoculated with AMF.

demands of establishing the symbiotic association did not negatively influence flowering. In fact, the number of flowers per inflorescence was generally increased by inoculation during both growing cycles of our study. In B. laxa, flowers for the current years growth are initiated after planting (Han and Halvey, 1993). Therefore, AMF colonization can not only influence inflorescence development directly, but it can also alter aspects of corm quality that indirectly affects flowering in the following growing cycle.

Colonization of plants by AMF can alter partitioning of biomass between different plant parts. The balance of biomass partitioning to daughter corms and cormels is important during the production of B. laxa bulbs. Asexual propagation via cormel production is generally low in Brodiaea (Han, 1993). Increased daughter corm weight is only beneficial when factors that influence multiplication (weight and number of cormels) is not negatively impacted. In addition to environmental factors, the size of the corm generally determines whether it will produce flowers or not (Halvey, 1990). The total weight of corms and cormels of $B$. laxa at the end of each growing cycle was significantly increased by both soil pasteurization and inoculation with AMF. Mora (1990) also reported increased bulb weight of $L$. longiflorum growing in pasteurized soil in response to inoculation with $G$. intraradices.
Flowering percentage and flower quality of $B$. laxa has been shown to increase with increasing corm size between 0.1-1.0 g, but are independent of weight for corms larger than $1.0 \mathrm{~g}$ (Han and Halvey, 1993; Han et al., 1990). We also found that AMF inoculation increased daughter corm weight and plants growing with AMF inoculum not only had significantly heavier daughter corms than noninoculated plants, but also had a higher proportion of total corm and cormel weight attributable to the weight of the daughter corm. Even though corm weights were over $1 \mathrm{~g}$, AMF still had a significant influence on flowering.

With onion, Charron et al. (2001) found that bulbs reached marketable size 2-3 weeks earlier when inoculated with AMF. In B. laxa most gains in bulb weight accumulates before anthesis (De Hertogh and Le Nard, 1993), therefore it is possible that increased flowering in B. laxa in response to AMF inoculation could have played a role in reducing average cormel weight without influencing flowering. The changes in biomass partitioning that we found in corms and cormels in response to AMF inoculation may influence the multiplication rate of the crop for bulb production.

Others (Clark and Zeto, 2000; Vázquez et al., 2001) have reported that AMF can increase plant $\mathrm{N}$ with no appreciable difference in plant $\mathrm{P}$ particularly in acidic soils. Enhanced acquisition of $\mathrm{Zn}, \mathrm{Ca}$, and $\mathrm{K}$ has also been reported for various plants colonized with different AMF isolates compared to nonAMF plants (Clark and Zeto, 2000). We found that the concentration of $\mathrm{P}$ and $\mathrm{S}$ in corms at the end of the first growing cycle was not significantly influenced by inoculation with AMF, but the total $\mathrm{P}$ content of corms was higher in AMF inoculated corms. This suggests that $\mathrm{P}$ and $\mathrm{S}$ may not have been limiting to plant growth under our cultural conditions, and that increased total $\mathrm{P}$ content in AMF inoculated corms was primarily a function of increased bulb weight in response to inoculation. Both the concentrations and total contents of $\mathrm{K}, \mathrm{Zn}$, and $\mathrm{N}$ in corms of B. laxa at the end of the first growing cycle were significantly increased by inoculation with AMF. Increased total $\mathrm{K}, \mathrm{Ca}$, $\mathrm{Zn}$, and $\mathrm{N}$ content and concentration along with increased corm weight suggests that AMF increased the uptake and storage of $\mathrm{K}, \mathrm{N}, \mathrm{Zn}$, and $\mathrm{Ca}$ in bulbs. Increased uptake of $\mathrm{N}, \mathrm{Zn}$, and $\mathrm{Ca}$ in plants colonized by AMF has been described for other plant species and have been associated with increased disease tolerance and dormancy in other bulb crops (De Hertogh and Le Nard, 1993). It is possible that increasing levels of these nutrients in B. laxa by inoculation with AMF may have beneficial influence on storage quality of corms.

Organic sources of carbon and nitrogen stored in bulbs at the end of a growing cycle are important for growth during the following season when storage reserves in mother corms are depleted by new growth. In developing storage organs such as corms, translocated photoassimilates are converted into carbon and nitrogen reserves such as starch, fructans, oils, and storage proteins (Kavakli et al., 2000). In $B$. laxa the primary area of storage is the 

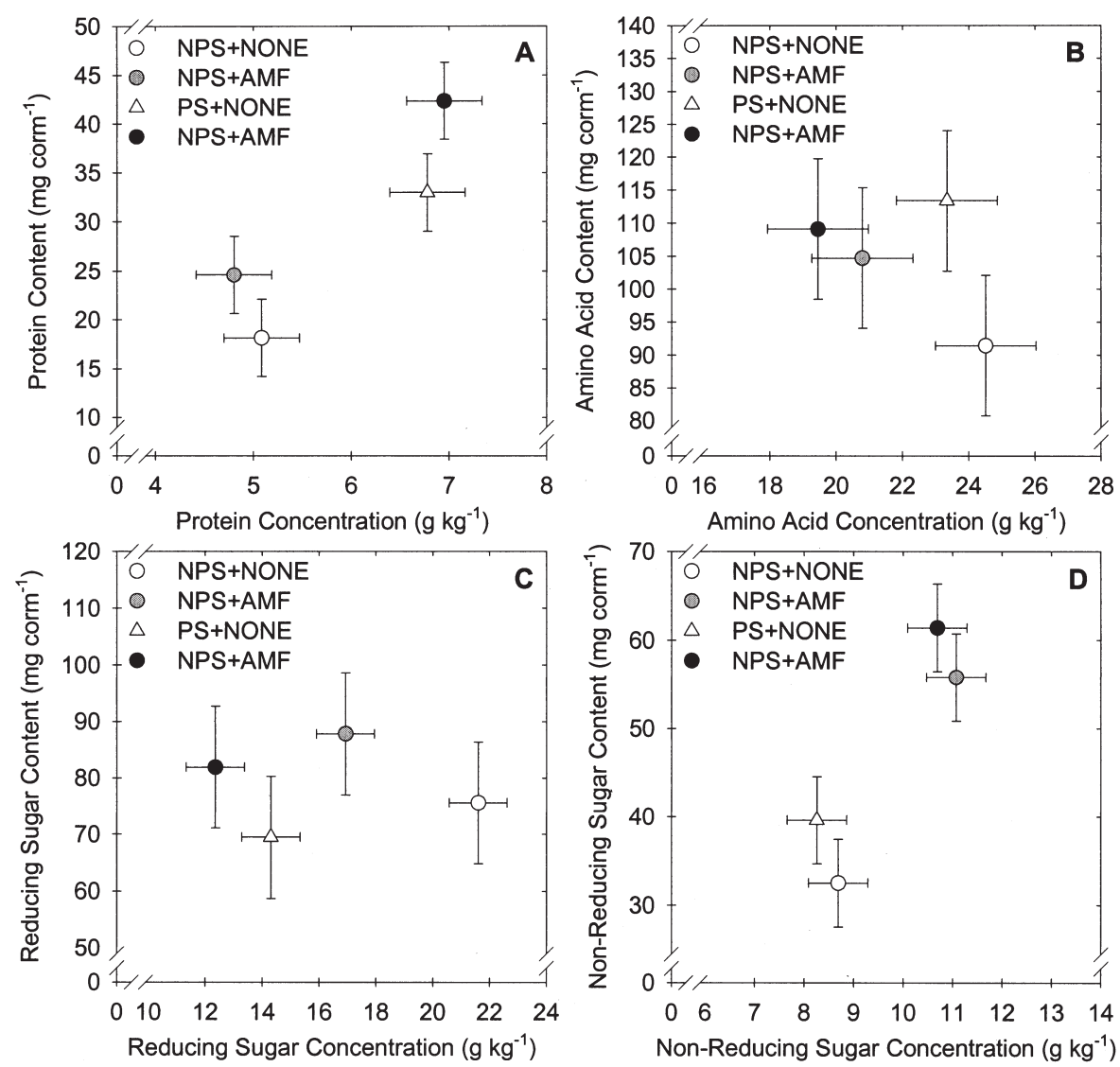

Fig. 5. Influence of soil pasteurization and inoculation with the arbuscular mycorrhizal fungus (AMF) Glomus intraradices on concentration and total content of protein (A), amino acids (B), reducing sugars (C), and nonreducing sugars (D) in daughter corms of Brodiaea laxa 'Queen Fabiola' at the end of the first growing cycle after inoculation. Error bars are standard error of the least squares means $(n=12)$. NPS+NONE = no soil pasteurization and sterilized AMF inoculum; NPS + AMF $=$ no soil pasteurization and inoculated with $\mathrm{AMF}$; $\mathrm{PS}+\mathrm{NONE}=$ pasteurized soil; $\mathrm{PS}+\mathrm{AMF}=$ pasteurized soil and inoculated with AMF.

basal plate, and the size of the apical meristem rather than just the reserves determines the corms' ability to form flowers (Halvey, 1990). At the end of the first growing cycle, we found that corms inoculated with AMF had significantly higher concentrations and total contents of nonreducing sugars than noninoculated corms indicating that AMF inoculated plants produced and stored more nonreducing sugars than noninoculated plants. Inoculation with AMF decreased amino acid and reducing sugar concentration in corms but changes in concentration were associated with proportional increases in total content and corm weight, therefore inoculation had no influence on amino acid or reducing sugar production and accumulation in corms. Others (Krishna and Bagyaraj, 1983) have reported that AMF increases accumulation of amino nitrogen concentrations in roots, however these studies were done with different AMF isolates and on annual plant species that do not accumulate storage reserves in a similar manner as geophytic species.

Total protein content of B. laxa corms generally decrease in response to cooling possibly as a result of respiratory turn-over (Le Nard et al., 1988). Increased accumulation of protein resulting from soil pasteurization can also influence storage quality of corms.
In our study, the concentration of protein in corms at the end of the first growing cycle was significantly increased by soil pasteurization and was not influenced by AMF inoculation. Soil pasteurization increased the concentration and total content of proteins in corms at the end of the first growing without increased corm weight, showing that soil pasteurization increased accumulation and storage of proteins in corms. Others (Krishna and Bagyaraj, 1983; Vázquez et al., 2001) have found that AMF can increase root and shoot total protein content, however responses depended on the species of AMF used in the study. In our study, we only used one isolate of AMF. It is possible that other AMF may alter corm total protein content.

Cultural treatments commonly used during bulb crop production to control detrimental organisms may not only influence the presence of natural populations of mycorrhizal fungi in soils, but also influence the effects of plant inoculation with AMF. Vosátka (1995) found that the growth response of onion to inoculation was higher when indigenous fungi in the soil were eliminated by steam sterilization. In our experiment colonization of inoculated plants was slightly decreased by soil pasteurization. However, flower production and biomass of corms and cormels were generally increased by pasteurization. The beneficial effects of AMF inoculation on flowering and corm/cormel production were generally increased by soil pasteurization, suggesting that although soil pasteurized decreased AMF colonization, either the efficiency of the symbiotic association was greater or pasteurization suppressed other organisms that were detrimental to plant growth.

\section{Conclusions}

Maximum productivity and quality of geophytes used for both flower and corm production requires a balance between resources allocated to flowering and corm production. The symbiotic relationship between arbuscular mycorrhizal fungi (AMF) and their plant symbiont can alter aspects of biomass partitioning and metabolism that differentially influence productivity and quality of corm crops. Inoculation of B. laxa 'Queen Fabiola' can decrease the time until flower opening and increase the number of flowers per inflorescence. Flowers on inoculated plants generally lasted longer. Inoculation can also increase daughter corm size and production of cormels, but inoculated plants preferentially increase biomass partitioning to daughter corms over cormels resulting in a lower average weight per cormel than in noninoculated plants. Our results indicate that adding AMF inoculum into the growing medium of $B$. laxa alters aspects of flowering and biomasses partitioning that are important in the commercial production of this crop for cut flowers and corms.

\section{Literature Cited}

Ames, R.N., R.G. Linderman, and T.C. Allen. 1976. Mycorrhizae in lily fields. The lily yearbook. 29:91-92.

Ames, R.N., and R.G. Linderman. 1977. Vesiculararbuscular mycorrhizae of Easter lily (Lilium longiflorum) in the northwestern United States. Can. J. Microbiol. 23:1663-1668.

Ames, R.N., and R.G. Linderman. 1978. The growth of Easter lily (Lilium longiflorum) as influenced by vesicular-arbuscular mycorrhizal fungi, Fusarium oxysporum, and fertility level. Can. J. Bot. 56:2773-2780.

Biermann, B.J. and R.G. Linderman. 1980. Quantifying vesicular-arbuscular mycorrhizae: A proposed method towards standardization. New Phytol. 87:63-67.

Bradford, M. 1976. A rapid and sensitive method for the quantification of microgram quantities of protein utilizing the principle of protein dye binding. Anal. Biochem. 72:248.

Bryla, D.R., and R.T. Koide. 1998. Mycorrhizal response of two tomato genotypes relates to their ability to acquire and utilize phosphorus. Ann. Bot. 82:849-857.

Charron, G., V. Furlan, M. Bernier-Cardou, and G. Doyon. 2001. Response of onion plants to arbuscular mycorhizae. 1. Effects of inoculation method and phosphorus fertilization on biomass and bulb firmness. Mycorrhiza 11:187-197.

Clark, R.B. and S.K. Zeto. 2000. Mineral acquisition by arbuscular mycorrhizal plants. J. Plant Nutr. 23:867-902.

De Hertogh, A.A. and M. Le Nard. 1993. The physiology of flower bulbs. Elsevier Sci. Publ., The Netherlands.

Dische, Z. 1962. Color reactions based on the reduc- 
ing properties of sugars, p. 512-514. In: R.L. Whistler and M.L. Wolfron. (eds.). Methods of carbohydrate chemistry, vol.1. Academic Press. N.Y.

Gaulak, R.G., D.A. Horneck, and R. O. Miller. 1997. Western states laboratory proficiency testing program: Soil and plant analytical methods. WREP. 125

Giovannetti, M. and S. Riess. 1980. Effects of soil applications of systemic fungicides on bulb formation in onions: Possible effect on the occurrence of vesicular-arbuscular mycorrhizal infection. Plant Soil 57:463-465.

Halvey, A.H. 1990. Recent advances in control of flowering and growth habit of geophytes. Acta Hort. 266:35-42.

Han, S.S. 1993. Chilling, ethephon, and photoperiod affect cormel production of Brodiaea. HortSci. 28:1095-1097.

Han, S.S. and A.H. Halvey. 1993. Triteleia, p. 611-616. In: A.A. De Hertogh and M. Le Nard. (eds.). The physiology of flowering bulbs. Elsiever Sci. Publ., The Netherlands.

Han, S.S., A.H. Halvey, R.M. Sachs, and M.S. Reid. 1990. Enhancement of growth and flowering of Triteleia laxa by ethylene. J. Amer. Soc. Hort. Sci. 115:482-486.

Han, S.S., A.H. Halevy, R.M. Sachs, and M.S. Reid. 1991. Flowering and corm yield of Brodiaea in response to temperature, photoperiod, corm size, and planting depth. J. Amer. Soc. Hort. Sci. 116:19-22.

Johnson, C.R., H.H. Graham, R.T. Leonard, and J.A. Menge. 1982. Effect of flower bud development in chrysanthemum on vesicular-arbuscular my- corrhizal formation. New Phytol. 90:671-675.

Kavakli, I.H., C.J. Slattery, H. Ito, and T.W. Okita. 2000. The conversion of carbon and nitrogen into starch and storage proteins in developing storage organs: An overview. Aust. J. Plant Physiol. 27:561-570.

Krishna, K.R. and D.J. Bagyaraj. 1983. Changes in the free amino nitrogen and protein factions of groundnut caused by inoculation with VA mycorrhizal. Ann. Bot. 51:399-401.

Le Nard, M., V. Fiala, Y. Querou, and E. Jolivet. 1988. Arginine as a molecular marker of physiological state of Tulipa gesneriana L. bulbs. Comptes rendus de l'Académie des Sciences, III, 307:557-562.

Linderman, R.G., R.N. Ames, and T.C. Allen. 1975. Studies of lily mycorrhizae. The lily yearbook. 28:62-64.

Marinangeli, P. and N. Curvetto. 1997. Bulb quality and traumatic acid influence bulblet formation from scaling in Lilium species and hybrids. Amer. Soc. Hort. Sci. 32:739-741.

Miller, W.B. and R.W. Langhans. 1989. Reduced irradiance affects dry weight partitioning in Easter lily. J. Amer. Soc. Hort. Sci. 114:306-309.

Mora, J.R.V. 1990. Effects of inoculations with pathogenic and beneficial microorganisms and ammonium or nitrate fertilization on easter lily growth. MS Thesis, Oregon State Univ., Corvallis.

Nelson, N. 1944. A photometric adaptation of the Somogyi method for determination of glucose. J. Biol. Chem. 153:375.

Phillips, J.M. and D.S. Hayman. 1970. Improved procedures for clearing roots and staining parasitic and vesicular-arbuscular mycorrhizal fungi for rapid assessment of infection. Trans. Br. Mycol. Soc. 55:158-161.

Rees, A.R. 1985. Ornamental bulbous plants, p. 288-293. In: A.H. Halevy (ed.). Handbook of flowering, vol. I. CRC Press, Boca Raton, Fla.

Scagel, C.F. 2002. Flowering and bulb quality of Liliaceous species in response to mycorrhizal fungi. 2001 Proc. Intl. Plant Prop. Soc. 51:280-286.

Smith, S.E. and D.J. Read. 1997. Mycorrhizal symbiosis, 2nd ed. Academic Press, San Diego.

Suh, J.K. 1997. Stem elongation and flowering response of Tulipa cultivars as influenced by bulb cooling, growth regulators and light quality. Acta Hort. 430:101-106.

Tawaraya, K., T. Imai, and T. Wagatsuma. 1999. Importance of root length in mycorrhizal colonization of welsh onion. J. Plant Nutr. 22:589-596.

Vázquez, M.M., J.M. Barea, and R. Azcón. 2001. Impact of soil nitrogen concentration on Glomus spp.-Sinorhizobium interactions as affecting growth, nitrate reductase activity and protein content of Medicago sativa. Biol. Fert. Soils 34:57-63.

Vosátka, M. 1995. Influence of inoculation with arbuscular mycorrhizal fungi on the growth and mycorrhizal infection of transplanted onion. Agr. Ecosys. Environ. 53:151-159.

Woomer, P.L. 1994. Most probable number counts, p. 59-79. In: R.W. Weaver (ed.). Methods of soil analysis, part 2. Soil Sci. Soc. Amer., Madison, Wis.

Yemm, E.W. and E.C. Cocking. 1955. The determination of amino acids with ninhydrin. Analyst 80:209-213. 